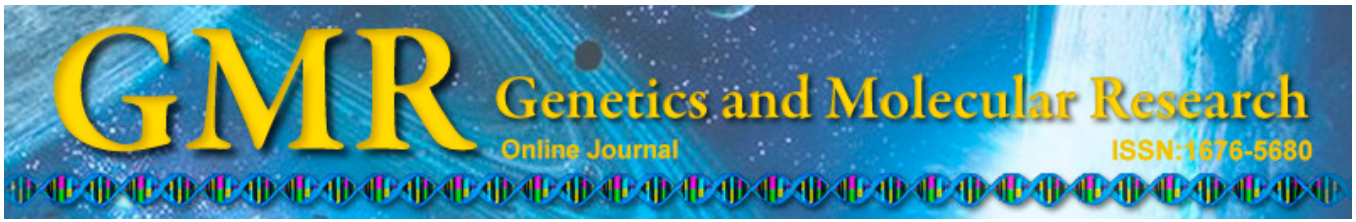

\title{
Characterization of agronomic and quality traits and HSW-G5 compositions from the progenies of common wheat (Triticum aestivum L.) with different protein content
}

\author{
M. Bian ${ }^{1}$, D.K. Sun ${ }^{2}$, D.F. Sun ${ }^{1,4}$ and G.L.Sun ${ }^{1,3}$ \\ ${ }^{1}$ College of Plant Science and Technology, Huazhong Agricultural University, \\ Wuhan, China \\ ${ }^{2}$ College of Biology, Wuhan University, Wuhan, China \\ ${ }^{3}$ Biology Department, Saint Mary's University, Halifax, Nova Scotia, Canada \\ ${ }^{4}$ Hubei Collaborative Innovation Center for Grain Industry, Wuhan, China \\ Corresponding author: D.F. Sun \\ E-mail: sundongfa1@mail.hzau.edu.cn
}

Genet. Mol. Res. 14 (1): 1975-1985 (2015)

Received January 15, 2014

Accepted June 27, 2014

Published March 20, 2015

DOI http://dx.doi.org/10.4238/2015.March.20.7

\begin{abstract}
High molecular weight glutenin subunits (HMW-GS) play an essential role in wheat processing quality. In this study, we evaluated the genetic pattern with HMW-GS composition between generations and examined whether agronomic and quality traits were correlated with each other. A wheat (Triticum aestivum L.) cultivar with high protein content and 2 cultivars with low protein content were subjected to a reciprocal cross. Sixteen agronomic and 4 quality characteristics were investigated. A total of 216 seeds from each F2 generation were chosen randomly and analyzed for HMW-GS composition using sodium dodecyl sulfate-polyacrylamide gel electrophoresis. Agronomic and quality characteristics were not significantly different
\end{abstract}


between reciprocal crosses, indicating no cytoplasmic effect on the characteristics studied. The separation ratio of $2 \mathrm{HMW}-\mathrm{GS}$ loci was 9:3:3:1, indicating no linkage between any 2 loci. The novel HMW-GS $\mathrm{N}$ was detected in cultivar R145, which did not follow the Mendelian segregation ratio. A Glu-A1a(1) band was not detected in 1 individual from Tian8901xR145. Average grain weight per spike was significantly correlated with quality characteristics and may be a suitable criterion for selecting high protein content in wheat breeding programs.

Key words: Common wheat; High-molecular weight glutenin subunit; Quality; Sodium dodecyl sulfate-polyacrylamide gel electrophoresis;

Triticum aestivum L.

\section{INTRODUCTION}

Wheat (Triticum aestivum L.) is one of the oldest cultivated crops in world and an important crop that offers substantial protein to human beings. Grain protein has a significant influence on processing quality, such as dough rheological properties, baking quality, and endproduct attributes (Buck et al., 2007). The level of global protein yield in wheat has remained relatively stable, despite an increase in productivity of this crop (Zlatska, 2005). Wheat quality improvement is a major challenge for many breeding programs.

Wheat flour proteins can be classified as albumin, globulin, prolamin, or glutenin (DuPont et al., 2005). Glutenin, a major class of storage proteins in the wheat endosperm, is classed into 2 groups: high molecular weight (HMW) glutenin and low molecular weight glutenin (LMW) (Payne et al., 1984). The HMW-glutenin subunits (GS) of common wheat are encoded by the Glu-A1, Glu-B1, and Glu-D1 loci on the long arms of homoeologous chromosome 1, each locus contains 2 tightly linked genes corresponding to a subunit of HMW and a subunit of LMW, termed x-type and y-type, respectively (Payne et al., 1980; Lawrence and Shepherd, 1981). The HMW-GS are particularly important for determining dough elasticity; the presence of specific HMW subunits is positively correlated with good bread-making quality (Anjum et al., 2007).

Since last century, great effort has been invested in identifying genetic information on HMW-GS and the relationships between quality traits and agronomic traits in order to predict bread wheat quality and provide theoretical guidance for wheat quality breeding (MacRitchie et al., 1990; Weegels et al., 1996). Alveograph and baking tests are labor-intensive and require large quantities of flour (Oury et al., 2010). Thus, agronomic characteristics that are correlated with quality characteristics offer indirect information for predicting wheat grain quality during early generations of the breeding process, although quality characteristics are significantly affected by environmental conditions (Noorka et al., 2009).

The objectives of this study were to investigate whether cytoplasm affects HMW-GS composition in progeny, as well as the relationships between agronomic characteristics and quality characteristics.

\section{MATERIAL AND METHODS}

\section{Plant materials and progeny production}

Three common wheat cultivars, differing significantly in protein content (protein con- 
tent was high in 1 cultivar and low in the other 2), were used in this study (Table 1). Reciprocal crosses were made between the high protein content parent and 2 low protein content parents in 2007. The 4 resulting F1 hybrids were planted in Kungming, Yunnan, China and self-pollinated to produce F2 generations. Three parents, their F1 hybrids, and F2 generations were sown into the experimental field of Huazhong Agricultural University in Wuhan, Hubei, China, with rows that were $1 \mathrm{~m}$ long and $20 \mathrm{~cm}$ wide, with 10 plants in each row. Seeds were harvested from a single plant in May 2008.

Five plants from each parent and F1 hybrids and all plants from the F2 generations were investigated for the agronomic and quality characteristics.

\section{Agronomic characteristic evaluation}

Sixteen agronomic characteristics were investigated in both parents and F1 generations including plant height (excluding awns), main spike length, length from the main spike to flag leaf pillow, length of the first internode, number of effective spikes (spike with more than 5 grains), number spikelets of the main spike, number of grains per plant, grain weight per plant, average grain weight per spike, 1000-kernel weight, flag leaf length, flag leaf width, area of flag leaf (leaf width $\mathrm{x}$ leaf length $\mathrm{x} 0.83$ ), photosynthesis rate, stomatal conductance, and transpiration rate. Ten characteristics were investigated in the F2 generation, including plant height, main spike length, length from the main spike to flag leaf pillow, length of the first internode, number of effective spikes, number spikelets on the main spike, number of grains per plant, grain weight per plant, average grain weight per spike, and 1000-kernel weight.

Photosynthesis rate, stomatal conductance, and transpiration rate were determined using the Li-6400 Photosynthesis System (Li-Cor Biosiences, Lincoln, NE, USA; photosynthetically active radiation was set to $1200 \mu \mathrm{mol} \cdot \mathrm{m}^{-2} \cdot \mathrm{s}^{-1}$ ) during the time from anthesis to grain filling.

\section{Quality evaluation}

Total protein, starch, and wet gluten content as well as Zeleny sedimentation value were determined using the Infratec ${ }^{\mathrm{TM}} 1241$ Grain Analyzer (FOSS, Eden Prairie, MN, USA) after harvest. The scanning temperature was controlled from $21^{\circ}-25^{\circ} \mathrm{C}$. The absorption wavelength range of the samples was $850-1050 \mathrm{~nm}$.

\section{Extraction and identification of HMW-GS}

A total of 216 seeds were randomly selected from each of the 4 F2 generations. Each seed was cut in half. The embryo-less half of the kernel from the F2 progeny was wrapped in filter paper and crushed using a hammer.

The HMW-GS extraction was prepared according to Liu et al. (2005) with the following modifications: whole meal was weighed in a $1.5-\mathrm{mL}$ centrifuge tube and extracted in $1 \mathrm{~mL}$ $50 \%$ 2-propanol (v/v) for 5 min under continuous vortex mixing, followed by incubation for $20 \mathrm{~min}$ at $65^{\circ} \mathrm{C}$, vortexing for $5 \mathrm{~min}$, and centrifugation for $5 \mathrm{~min}$ at $1100 \mathrm{rpm}$. The supernatant was discarded. This procedure was repeated 3 times to remove the gliadin proteins. Solution B1 (2\% dithiothreitol, $40 \%$ Tris-HCl, $50 \%$ 2-propanol, $2 \%$ sodium dodecyl sulfate (SDS), pH 8.0) was added to the residue at a $1 \mathrm{mg} / 5 \mu \mathrm{L}$ ratio. The mixture was incubated for $30 \mathrm{~min}$ at $65^{\circ} \mathrm{C}$. Equal amounts of solution B2 (1.4\% 4-vinylpyridine, $40 \mathrm{~mL}$ Tris- $\mathrm{HCl}, 50 \%$ 2-propanol, 
$2 \% \mathrm{SDS}, \mathrm{pH} 8.0$ ) was added to the mixture, followed by incubation for $15 \mathrm{~min}$ at $65^{\circ} \mathrm{C}$. After 5 min vortexing and $4000 \mathrm{rpm}$ centrifugation, a $100 \mu \mathrm{L}$ supernatant was mixed into a $100 \mu \mathrm{L}$ extraction solution ( $2 \%$ SDS, $6.25 \mathrm{~mL}$ Tris- $\mathrm{HCl}, 44 \%$ glycerol, $0.05 \%$ bromophenol blue, $5 \%$ $\beta$-mercaptoethanol, $\mathrm{pH} 6.8$ ) and incubated at $100^{\circ} \mathrm{C}$ for $5 \mathrm{~min}$, followed by centrifugation for $10 \mathrm{~min}$ at $4000 \mathrm{rpm}$.

The HMW-GS extraction was analyzed using 12\% SDS-PAGE electrophoresis. Chinese spring $(7+8,2+12)$ was used as a control. PageRuler unstained protein ladder (\#SM0661, Fermentas, Vilnius, Lithuania) was used as the molecular weight marker. Bovine serum albumin was also used to determine the concentrations of the subunits. HMW-GS were identified based on the numbering system developed by Payne and Lawrence (1983). Gels were scanned using the AlphaImager EP (NatureGene Corp., Beijing, China).

\section{Statistical analysis}

The data was analyzed using SAS System for Windows v6.12 (SAS Institute Inc., Cary, NC, USA) and the Excel software. Correlations between the agronomic and quality characteristics were determined based on Pearson's correlation coefficient values.

\section{RESULTS}

\section{Agronomic characteristics and quality characteristics of parents and F1 hybrids}

The 3 parents varied significantly in the 7 characteristics studied, including plant height, main spike length, number of grains per plant, grain weight per plant, average grain weight per spike, width of flag leaf, and length of flag leaf $(\mathrm{P} \leq 0.01)$. Quality characteristics of the 3 parents also significantly differed $(\mathrm{P} \leq 0.01)$ (Table 1$)$. No significant difference between F1 reciprocal crosses was found for the agronomic or quality characteristics.

\begin{tabular}{|c|c|c|c|c|c|c|}
\hline \multirow[t]{2}{*}{ Name } & \multirow[t]{2}{*}{ Origin } & \multirow{2}{*}{$\begin{array}{l}\text { HMW-GS } \\
\text { composition }\end{array}$} & \multicolumn{4}{|c|}{ Means \pm SD } \\
\hline & & & $\begin{array}{c}\text { Protein } \\
\text { content }(\%)^{* *}\end{array}$ & $\begin{array}{c}\text { Starch } \\
\text { content }(\%)^{* *}\end{array}$ & $\begin{array}{l}\text { Wet gluten } \\
\text { content }(\%)^{* *}\end{array}$ & $\begin{array}{c}\text { Zeleny sedimentation } \\
\text { value }(\mathrm{mL})^{* *}\end{array}$ \\
\hline Tian8901 & Tianjing, China & $1.7+8.5+10$ & $15.26 \pm 0.9343^{\mathrm{a}}$ & $52.963 \pm 1.2863^{\mathrm{a}}$ & $29.1328 \pm 1.3583^{\mathrm{a}}$ & $46.1585 \pm 2.060^{\mathrm{a}}$ \\
\hline R145 & France & $1.14+15.2+12 . \mathrm{N}$ & $11.56 \pm 0.4879^{b}$ & $57.7212 \pm 1.2707^{\mathrm{b}}$ & $24.5309 \pm 0.7353^{b}$ & $32.4448 \pm 1.6536^{\mathrm{b}}$ \\
\hline E51125 & Hubei, China & $7+9,5+10$ & $11.12 \pm 0.2168^{\mathrm{b}}$ & $58.6634 \pm 0.9032^{\mathrm{b}}$ & $24.4008 \pm 0.3374^{b}$ & $32.2592 \pm 2.1621^{\mathrm{b}}$ \\
\hline
\end{tabular}

Means with the same letter were not significantly different **Significance at $\mathrm{P}=0.01$ level of probability, respectively.

\section{Correlation analyses of quality and agronomic characteristics}

Starch was negatively correlated with protein, wet gluten, and Zeleny sedimentation value. Positive correlations among protein, wet gluten, and Zeleny were detected with coefficients higher than 0.9 ( $\alpha=0.01$, data not shown). A significant correlation was observed between quality characteristics in all $4 \mathrm{~F} 2$ crosses.

Correlation analysis between agronomic characteristics and quality characteristics showed that most agronomic characteristics were negatively correlated with protein content. 
Plant height, main spike length, length from the main spike to flag leaf pillow, length of the first internode, number of grains per plant, grain weight per plant, average grain weight per spike, and 1000-kernel weight were negatively correlated with protein content, wet gluten content, and Zeleny sedimentation value, but were positively correlated with starch content. Main spike length, number of grains per plant, and number of effective spikes were positively correlated with protein content, wet gluten content, and Zeleny sedimentation value, but negatively correlated with starch content. Of these characteristics, average grain weight per spike was significantly correlated with quality characteristics at the level of 0.001 .

\section{HMW-GS composition}

\section{Parents and F1 hybrids}

The high protein content cultivar Tian8901 was reciprocally crossed with 2 low protein content cultivars, R145 and E51125. The F1 hybrids and 216 seeds from each F1 cross were analyzed by SDS-PAGE. The HMW-GS compositions of the 3 parents are shown in Table 1. A novel HMW-GS was detected in cultivar R145, with a molecular weight of $83 \mathrm{kD}$, which was referred to as $\mathrm{N}$ (Figure 1, lane 3). N showed 2 closely linked bands on 12\% SDS-PAGE.

The HMW-GS compositions of F1 hybrids were also analyzed. The results revealed that the HMW-GS bands from both parents expressed in the F1 hybrids. The subunits in the F1 hybrids were genetically codominant in all 4 crosses and showed a dosage effect. The bands of the same subunit differed in the F1 hybrids between reciprocal crosses. The bands from female parents were darker than those from male parents, indicating that the effect of the subunit from female parents was higher than that from male parents (Figure 1). This result was consistent with those of Uhlen and Ringlund (1987).

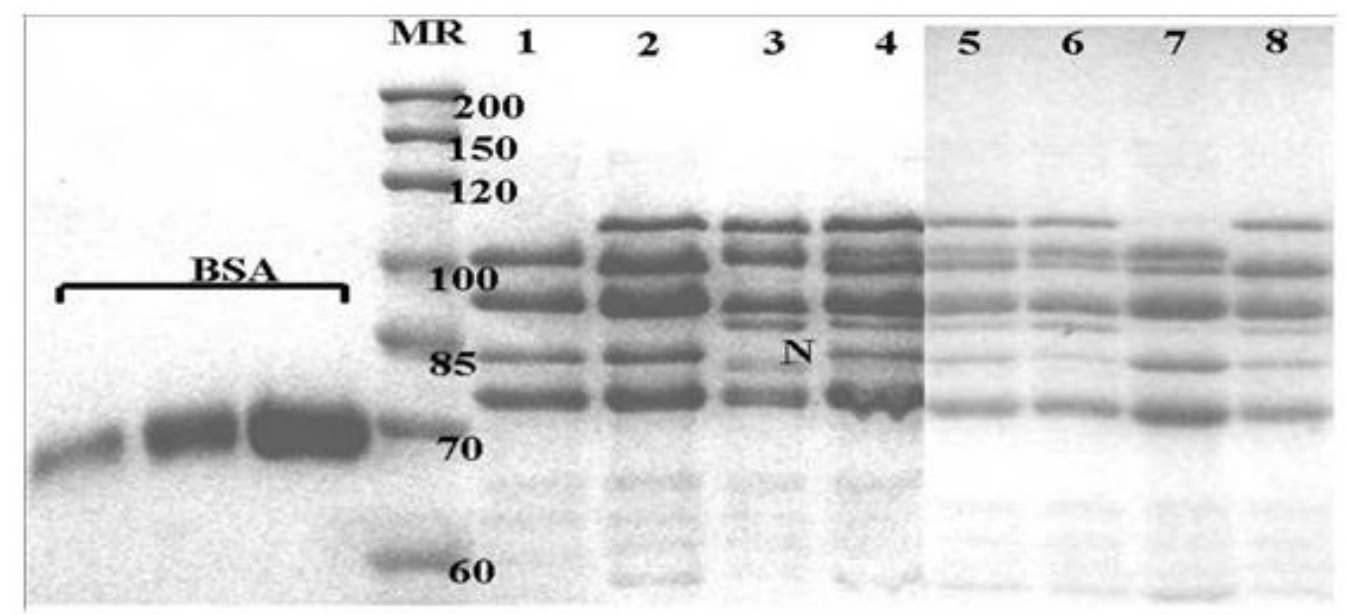

Figure 1. High molecular weight glutenin subunit was detected in the progeny of Tian8901xR145. BSA: Bovine serum albumin, lane MR: Protein molecular marker, lane 1: Chinese spring, lane 2: Tian8901, lane 3: R145, lane 4: Tian8901xR145 F1 hybrid, lanes 5-8: Tian8901xR145 F2 progenies, the sample in lane 7 missing Glu-A1a(1) band, $\mathrm{N}$ : high molecular weight glutenin subunit $\mathrm{N}$. 


\section{HMW-GS composition of F2 generations}

Nine types of HMW-GS composition were observed in Tian8901xR145 and R145xTian8901 crosses, and 6 types in Tian8901xE51125 and E51125xTian8901 crosses. Their subunit compositions and percentage are listed in Table 2.

The ratio of present and absent for each HMW-GS bands was close to 3:1 in all F2 populations, including Glu-A1a(1), Glu-D1a(2+12), Glu-D1d(5+10), Glu-B1b(7+8), Glu-B1h(14+15), and Glu-B1c(7+9). No significant difference was observed between reciprocal crosses for each HMW-GS band $(\mathrm{P}>0.05)$ (Table 3$)$. The HMW-GS N in cultivar R145 did not fit Mendelian segregation ratio in the Tian8901xR145 and R145xTian8901 F2 generations. One individual from the Tian $8901 \times R 145$ population did not show the Glu-A1a(1) band (Figure 1). The ratio of any 2 HMW-GS loci segregation were as follows 9:3:3:1 ratio, indicating no linkage between any 2 loci. The ratio of female parent type, heterozygous type, and male parent type was 1:14:1 in the Tian8901xR145 and R145xTian8901 crosses, while the ratio was 3:12:1 in the Tian8901xE51125 cross and 1:12:3 in the E51125xTian8901 cross.

Table 2. Subunit compositions and percentage in 4 crosses.

\begin{tabular}{|c|c|c|c|c|c|}
\hline \multicolumn{4}{|c|}{ Subunit composition } & \multicolumn{2}{|c|}{ Percentage (\%) } \\
\hline & & & & Tian8901xR145 & R145xTian8901 \\
\hline \multirow[t]{2}{*}{$2+12$} & $5+10$ & $7+8$ & $14+15$ & 25.93 & 26.39 \\
\hline & $5+10$ & $7+8$ & $14+15$ & 13.43 & 12.04 \\
\hline $2+12$ & & $7+8$ & $14+15$ & 10.19 & 9.26 \\
\hline $2+12$ & $5+10$ & & $14+15$ & 12.96 & 15.74 \\
\hline \multirow[t]{3}{*}{$2+12$} & $5+10$ & $7+8$ & & 11.57 & 13.43 \\
\hline & $5+10$ & & $14+15$ & 11.11 & 6.02 \\
\hline & $5+10$ & $7+8$ & & 5.56 & 5.09 \\
\hline $2+12$ & & & $14+15$ & 5.56 & 6.02 \\
\hline \multirow[t]{2}{*}{$2+12$} & & $7+8$ & & 3.7 & 6.02 \\
\hline & & & & Tian8901xE51125 & E51125xTian8901 \\
\hline $5+10$ & & $7+8$ & $7+9$ & 41.2 & 37.96 \\
\hline $5+10$ & & $7+8$ & $7+9$ & 10.19 & 10.65 \\
\hline $5+10$ & & & $7+9$ & 16.67 & 18.98 \\
\hline $5+10$ & & $7+8$ & & 17.13 & 21.3 \\
\hline $5+10$ & & & $7+9$ & 7.41 & 7.87 \\
\hline $5+10$ & & $7+8$ & & 7.41 & 3.24 \\
\hline
\end{tabular}

Table 3. Presence and absence of separating subunits in different crosses.

\begin{tabular}{|c|c|c|c|c|c|c|}
\hline \multirow[t]{2}{*}{ Subunit } & \multicolumn{2}{|c|}{ Present } & \multicolumn{2}{|c|}{ Absent } & \multicolumn{2}{|c|}{ Chi-square } \\
\hline & Tian8901xR145 & R145xTian8901 & Tian8901xR145 & R145xTian8901 & Tian8901xR145 & R145xTian8901 \\
\hline $2+12$ & 152 & 166 & 64 & 50 & 2.228395 & 0.302469 \\
\hline $5+10$ & 173 & 170 & 43 & 46 & 2.722222 & 1.388889 \\
\hline $7+8$ & 152 & 156 & 64 & 60 & 2.228395 & 0.746914 \\
\hline \multirow[t]{2}{*}{$14+15$} & 171 & 163 & 45 & 53 & 1.783951 & 0.006173 \\
\hline & Tian8901xE51125 & E51125xTian8901 & Tian8901xE51125 & E51125xTian8901 & Tian8901xE51125 & E51125xTian8901 \\
\hline 1 & 162 & 169 & 54 & 47 & 0.006173 & 1.04321 \\
\hline 8 & 164 & 158 & 52 & 58 & 0.055556 & 0.302469 \\
\hline 9 & 163 & 163 & 53 & 53 & 0.006173 & 0.006173 \\
\hline
\end{tabular}




\section{DISCUSSION}

\section{HMW-GS composition}

In the present study, HMW-GS bands from both parents of each cross were completely expressed in the F1 hybrids. The band density of the same subunit differed in the F1 hybrids between reciprocal crosses. Those from female parents were darker than those from male parents, indicating that the maternal parent had a greater effect on the expression of HMW-GS in F1 hybrids than the paternal parent (Figure 1, 2, 3, and 4). This is because the sperm fuses with 2 polar nuclei to form a triploid ( $3 n$ ) nucleus known as the primary endosperm nucleus during double fertilization. F1 hybrid subunits were genetically codominant. HMW-GS are encoded by loci on the long arms of homoeologous group 1 chromosomes (Payne et al., 1980; Galili and Feldman, 1984), while there were some new loci reported to be the regulators of the HMW glutenins (Wanous et al., 2003; Jin et al., 2009; Storlie et al., 2009). In the present study, segregation of HMW-GS loci in 4 crosses followed the Mendelian law of independent segregation, suggesting no linkage between any 2 loci. Our results corresponded well with the previous hypothesis that HMW-GS genes exhibit simple co-dominant Mendelian inheritance (Payne, 1987; Payne et al., 1981, 1987).

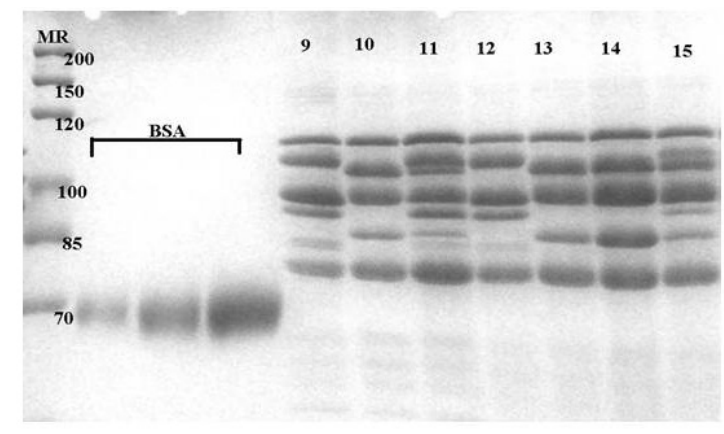

Figure 2. High molecular weight glutenin subunit was detected in the progeny of R145xTian8901.BSA: Bovine serum albumin, lane MR: Protein molecular marker, lane 9: R145, lane 10: Tian8901, lane 11: F1 R145xTian8901 hybrid, lanes 12-15: R145xTian8901 F2 progenies.

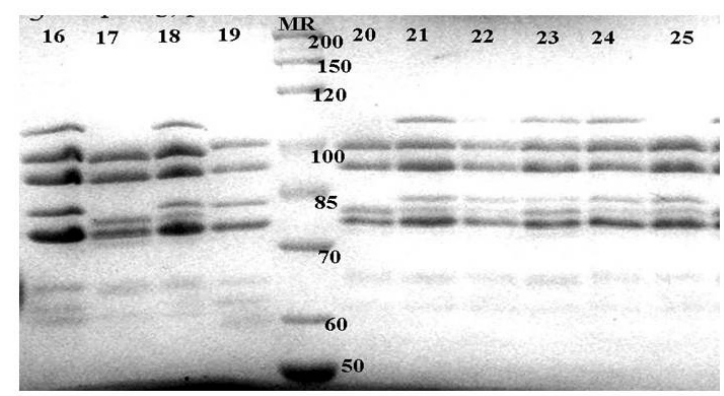

Figure 3. High molecular weight glutenin subunit was detected in the progeny of Tian8901xE51125. BSA: Bovine serum albumin, lane MR: protein molecular marker, lane 16: Tian8901, lane 17: E51125, lane 18: Tian8901xE51125 F1 hybrid, lane 19: Chinese spring, lanes 20-25: Tian8901xE51125 F2 progenies. 


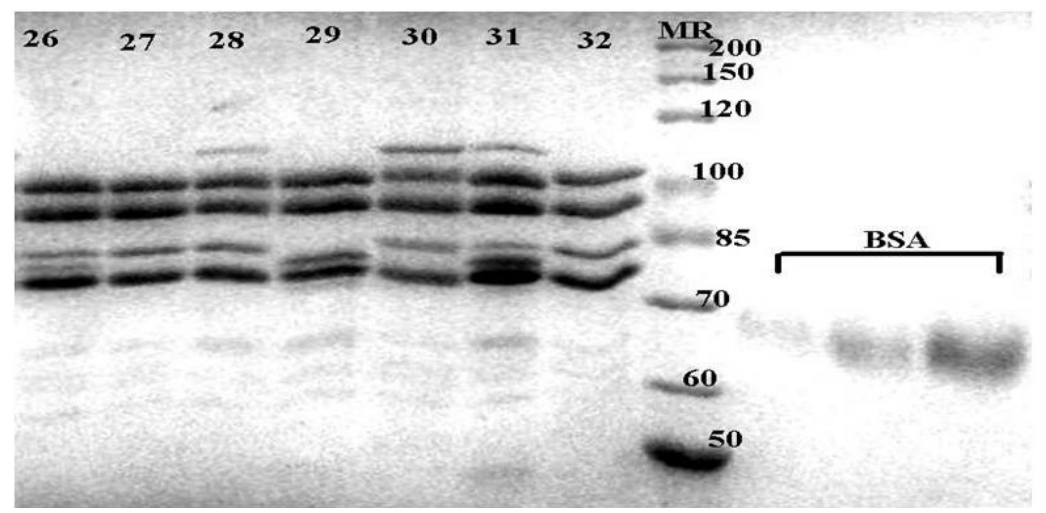

Figure 4. High molecular weight glutenin subunit was detected in the progeny of E51125xTian8901. BSA: Bovine serum albumin, lane MR: Protein molecular marker, lanes 26-28: E51125xTian8901 F2 progenies, lane 29: E51125, lane 30: Tian8901, lane 31: E51125xTian8901 F1 hybrid, lane 32: Chinese spring.

In the present study, 1 individual in the Tian8901xR145 F2 generation did not show the Glu-A1a(1) band (Figure 1, lane 7), while both parents showed this band. Previous studies found that the missing mechanism was associated with the presence of a premature stop codon within the coding region (De Bustos et al., 2000; Wan et al., 2002; Sun et al., 2004). This may be because of the insertion of a transposon-like element in the coding region (Harberd et al., 1987; Lafiandra et al., 1997; Yuan et al., 2009). Lafiandra et al. (1997) reported that an ancestral active subunit 1 gene was silenced by the insertion of the 8-kb transposon-like fragment into the linked y-type gene. The cause of the missing Glu-A1a(1) in our study requires further study.

HMW-GS were controlled by genes at the long arms of the chromosomes 1D and 1B. Six genes, 1Ax, 1Ay, 1Bx, 1By, 1Dx, and 1Dy reportedly control HMW-GSs (Bietz et al., 1975). Common wheat typically expresses 3-5 HMW subunits because of gene silencing (Payne and Lawrence, 1983; Payne et al., 1987; Anjum et al., 2007). However, some cultivars contain more than 5 subunits (Johansson et al., 1993; Buonocore et al., 1996; Anjum et al., 2000). In the present study, cultivar R145 was found to have 6 subunits, including subunit $\mathrm{N}$ with 2 closely linked bands detected on 12\% SDS-PAGE. Further study is required to determine the influence of the glutenin subunit $\mathrm{N}$ on processing quality. Subunit $\mathrm{N}$ did not fit the Mendelian segregation ratio. The presence to absence ratio was observed to be 116:100 and 138:78 in the Tian8901xR145 and R145xTian8901 F2 generations, respectively.

\section{Agronomic and quality characteristics}

Cytoplasmic inheritance studies on agronomic characteristics and quality characteristics often show contradictory results. In the present study, neither agronomic characteristics nor quality characteristics showed a significant difference between reciprocal crosses, indicating no cytoplasmic effect on these characteristics. This result is consistent with those of Atienza et al. (2007) who reported that reciprocal F1 lines did not differ for any of the agronomic traits evaluated with the exception of anthesis date, but disagreed with those of Ekiz et al. (1998) and Rajcan et al. (2002) who reported significant differences in reciprocal crosses for 1000-kernel weight, protein content, grain hardness, and days to maturity in some crosses. 
Correlation between different characteristics generally results from the presence of linked genes and the epistatic effect of different genes (Mohsin et al., 2009; Yucel et al., 2009). In the present study, positive correlations among protein, wet gluten, and Zeleny were detected with coefficients $>0.9(\alpha=0.01$, data not shown). The result is consistent with those of various previous studies (Cesevičienė et al., 2009; Hrušková and Švec, 2009).

Most agronomic characteristics were negatively correlated with protein; only main spike length, number of grains per plant, and number of effective spike were positively correlated, which corresponds well with the results of previous studies (McNeal et al., 1982; Holland et al., 2001; Khattak et al., 2005). We also found significant correlation between average grain weight per spike and quality characteristics at the level of 0.001 . This result is consistent with the finding of Dağustü (2008). A decrease in average grain weight per spike was directly associated with increased protein content, wet gluten content, and Zeleny sedimentation value.

In conclusion, the HMW-GS composition of different generations was examined. Separations followed Mendelian laws of independent assortment, suggesting no linkage between any 2 loci. This result agrees with those of previous reports. A novel glutenin subunit identified in this study did not fit the Mendelian segregation ratio and contained 2 closely linked bands in the F2 generations. One individual in the F2 generation did not show the GluA1a(1) band, while both the parents showed the Glu-A1a(1) band. Correlation analyses found that decreased average grain weight per spike was directly associated with increased protein content, wet gluten content, and Zeleny sedimentation value.

\section{ACKNOWLEDGMENTS}

Research supported by the the "863" China High-Tech Research Project grant (\#2011AA10A106) and National Natural Science Foundation of China (\#30971777).

\section{REFERENCES}

Anjum FM, Lookhart GL and Walker CE (2000). High-molecular-weight glutenin subunit composition of Pakistani hard white spring wheats grown at three locations for 2 years and its relationship with end-use quality characteristics. $J$. Sci. Food Agric. 80: 219-225.

Anjum FM, Khan MR, Din A, Saeed M, et al. (2007). Wheat gluten: high molecular weight glutenin subunits - structure, genetics, and relation to dough elasticity. J. Food Sci. 72: 56-63.

Atienza S, Ramírez M, Martín A and Ballesteros J (2007). Effects of reciprocal crosses on agronomic performance of tritordeum. Rus. J. Genet. 43: 865-868.

Bietz JA, Shepherd KW and Wall JS (1975). Single-kernel analysis of glutenin: use in wheat genetics and breeding. Cereal Chem. 52: 513-532.

Buck HT, Nisi JE and Salomon N (2007). Wheat production in stressed environments. Developments in Plant Breeding. Springer: Dordrecht, the Netherlands, 12: 519-526.

Buonocore F, Hickman DR, Caporale C, Porceddu E, et al. (1996). Characterisation of a novel high molecular glutenin subunit encoded by chromosome 1D of bread wheat. J. Cereal Sci. 23: 55-60.

De Bustos A, Rubio P and Jouve N (2000). Molecular characterisation of the inactive allele of the gene Glu-A1 and the development of a set of AS-PCR markers for HMW glutenins of wheat. Theor. Appl. Genet. 100: 1085-1094.

Cesevičienè J, Leistrumaitė A and Paplauskienė V (2009). Grain yield and quality of winter wheat varieties in organic agriculture. Agron. Res. 7: 217-223.

Dağustü N (2008). Genetic analysis of grain yield per spike and some agronomic traits in diallel crosses of bread wheat (Triticum aestivum L.). Turkish. J. Agric. For. 32: 249-258.

De Bustos A, Rubio P and Jouve N (2000). Molecular characterisation of the inactive allele of the gene Glu-A1 and the development of a set of AS-PCR markers for HMW glutenins of wheat. Theor. Appl. Genet. 100: 1085-1094.

DuPont FM, Chan R, Lopez R and Vensel WH (2005). Sequential extraction and quantitative recovery of gliadins, 
glutenins, and other proteins from small samples of wheat flour. J. Agric. Food Chem. 53: 1575-1584.

Ekiz H, Kiral A, Akçin A and Simsek L (1998). Cytoplasmic effects on quality traits of bread wheat (Triticum aestivum L.). Euphytica 100: 189-196.

Galili G and Feldman M (1984). Mapping of glutenin and gliadin genes located on chromosome 1B of common wheat. Mol. Gen. Genet. 193: 293-298.

Harberd NP, Flavell RB and Thompson RD (1987). Identification of a transposon-like insertion in a Glu-1 allele of wheat. Mol. Gen. Genet. 209: 326-332.

Holland JB, Frey KJ and Hammond EG (2001). Correlated responses of fatty acid composition, grain quality and agronomic traits to nine cycles of recurrent selection for increased oil content in oat. Euphytica 122: 69-79.

Hrušková M and Švec I (2009). Wheat hardness in relation to other quality factors. Czech. J. Food Sci. 27: 240-248.

Jin W, Liu J, Wu F and Guo A (2009). Cloning of high molecular weight gluten subunit promoter and study on its function in wheat. Braz. Arch. Biol. Techn. 52: 265-270.

Johansson E, Henriksson P, Svensson G and Heneen WK (1993). Detection, chromosomal location and evaluation of the functional value of a novel high Mr glutenin subunit found in Swedish wheats. J. Cereal Sci. 17: 237-245.

Khattak AB, Jabbar A, Khan M, Bibi N, et al. (2005). Evaluation of physical and chemical characteristics of newly evolved wheat cultivars. J. Sci. Food Agric. 85: 1061-1064.

Lafiandra D, Tucci GF, Pavoni A, Turchetta T, et al. (1997). PCR analysis of x- and y-type genes present at the complex Glu-A1 locus in durum and bread wheat. Theor. Appl. Genet. 94: 235-240.

Lawrence GL and Shepherd KW (1981). Inheritance of glutenin protein subunits of wheat. Theor. Appl. Genet. 60: 333-337.

Liu L, He ZH, Yan J, Zhang Y, et al. (2005). Allelic variation at the Glu-1 and Glu-3 loci, presence of the 1B.1R translocation, and their effects on mixographic properties in Chinese bread wheats. Euphytica. 142: 197-204.

MacRitchie F, Du Cros DL and Wrigley CW (1990). Flour polypeptides related to wheat quality. Adv. Cereal Sci. Technol. 10: 79-145.

McNeal FH, McGuire CF and Klindworth DL (1982). Agronomic and quality characteristics of spring wheat lines selected for protein content and protein yield. Euphytica 31: 377-381.

Mohsin T, Khan N and Naqvi FN (2009). Heritability, phenotypic correlation and path coefficient studies for some agronomic characters in synthetic elite lines of wheat. J. Food Agric. Environ. 7: 278-282.

Noorka IR, Salim Ur R, Haidry JR, Khaliq I, et al. (2009). Effect of water stress on physico-chemical properties of wheat (Triticum aestivum L.). Pak. J. Bot. 41: 2917-2924.

Oury FX, Chiron H, Faye A, Gardet O, et al. (2010). The prediction of bread wheat quality: joint use of the phenotypic information brought by technological tests and the genetic information brought by HMW and LMW glutenin subunits. Euphytica 171: 87-109.

Payne PI (1987). Genetics of wheat storage proteins and the effect of allelic variation of bread-making quality. Ann. Rev. Plant Physiol. 38: 141-153.

Payne PI and Lawrence GJ (1983). Catalogue of alleles for the complex gene loci, Glu-A1, Glu-B1, and Glu-D1 which code for high-molecular-weight subunits of glutenin in hexaploid wheat. Cereal Res. Commun. 11: 29-35.

Payne PI, Law CN and Mudd EE (1980). Control by homoeologous group 1 chromosomes of the high-molecular-weight subunits of glutenin, a major protein of wheat endosperm. Theor. Appl. Genet. 58: 113-120.

Payne PI, Holt LM and Law CN (1981). Structural and genetical studies on the high-molecular-weight subunits of wheat glutenin. 1. Allelic variation in subunits amongst varieties of wheat (Triticum aestivum). Theor. Appl. Genet. 60: 229-236.

Payne PI, Holt LM, Jackson EA and Law CN (1984). Wheat storage proteins: their genetics and their potential for manipulation by plant breeding. Phil. Trans. Royal Soc. London. B 304: 359-371.

Payne PI, Nightingale MA, Krattiger AF and Holt LM (1987). The relationship between HMW glutenin subunit composition and the bread-making quality of British-grown wheat varieties. J. Sci. Food Agric. 40: 51-65.

Rajcan I, Kasha KJ, Kott LS and Beversdorf WD (2002). Evaluation of cytoplasmic effects on agronomic and seed quality traits in two doubled haploid populations of Brassica napus L. Euphytica 123: 401-409.

Storlie EW, Ihry RJ, Baehr LM, Tieszen KA, et al. (2009). Genomic regions influencing gene expression of the HMW glutenins in wheat. Theor. Appl. Genet. 118: 295-303.

Sun MM, Yan YM, Yi J, Xiao YH, et al. (2004). Molecular cloning and comparative analysis of a y-type inactive HMW glutenin subunit gene from cultivated emmer wheat (Triticum dicoccum L.). Hereditas 141: 46-54.

Uhlen AK and Ringlund K (1987). Gene dosage effects on storage proteins in wheat (Triticum aestivum). J. Cereal Sci. 6: 219-223.

Wan Y, Wang D, Shewry PR and Halford NG (2002). Isolation and characterization of five novel high molecular weight subunit of glutenin genes from Triticum timopheevi and Aegilops cylindrica. Theor. Appl. Genet. 104: 828-839.

Wanous MK, Munkvold JD, Kruse JD, Brachman EE, et al. (2003). Identification of chromosome arms influencing 
expression of the HMW glutenins in wheat. Theor. Appl. Genet. 106: 213-220.

Weegels PL, Hamer RJ and Schofield JD (1996). Functional properties of wheat glutenin. J. Cereal Sci. 23: 1-18.

Yuan ZW, Chen QJ, Zhang LQ, Yan ZH, et al. (2009). Molecular Characterization of Two Silenced y-type Genes for Glu-B1 in Triticum aestivum ssp. yunnanese and ssp. tibetanum. J. Integrative Plant Biol. 51: 93-99.

Yucel C, Baloch FS and Ozkan H (2009). Genetic analysis of some physical properties of bread wheat grain (Triticum aestivum L. em Thell). Tur. J. Agric. For. 33: 525-535.

Zlatska AV (2005). Grain protein content in wheat: Genetics of the character and some predictions for its improvement in common wheat. Russ. J. Gen. 41: 823-834. 